\title{
The State of Pharmaceutical Manufacturing in the Democratic Republic of Congo: The Journey so Far
}

Melody Okereke, BPharm (in view), mini-MBA

Faculty of Pharmaceutical Sciences, University of Ilorin, Kwara State, Nigeria

\begin{abstract}
Despite a population of over 89 million people, the Democratic Republic of Congo (DRC) has just 30 local pharmaceutical manufacturers (DRC) with the majority of manufacturers based in Kinshasa, the capital city. Of the total number of pharmaceutical products sold in the DRC, just 10\% accounts for those manufactured locally. The DRC remains dependent on other countries such as China and India for the supply of active pharmaceutical ingredients (APIs) -thus, local pharmaceutical manufacturing is therefore reliant on imported commodities and industrial machinery. Given the relevance of the pharmaceutical industry, it is vital to pay careful attention to the problems affecting it. Here, we assess the current situation of pharmaceutical manufacturing in the DRC, examine current challenges, and provide solutions for future development.
\end{abstract}

Keywords: DRC, Congo, Pharmaceutical, Manufacturing, COVID-19, Drug Importation

\section{Introduction}

Despite having a population of over 93 million, just 30 local pharmaceutical manufacturers (LPMs) exist in the Democratic Republic of Congo (DRC). Just $10 \%$ of pharmaceutical commodities consumed in the country are manufactured locally, and most manufacturers are located in Kinshasa, the capital city. Since the local production of industrial machinery, active pharmaceutical ingredients (APIs), and other manufacturing resources has not received national health priority, the pharmaceutical manufacturing capacity of the DRC is deficient in meeting national demands which has forced the country to be reliant on other countries such as China and India for the supply of APIs and other necessary pharmaceutical commodities. As a result, the levies incurred due to importations raise prices and reduce price competitiveness, which discourages local manufacturing. In the DRC, pharmaceutical manufacturing has been surmounted with additional challenges such as erratic and costly utilities, high costs of transportation, political instability, and corruption. Given the relevance of the pharmaceutical industry, it is vital to pay careful attention to the problems affecting it.

\section{Country Background}

With over 93 million population as of 18th December 2021, the DRC is currently the fourth largest country in Africa [1]. The country is regarded as a significant African regional confluence, bordered to the north by Central African Republic (CAR) and South Sudan; to the east by Burundi, Rwanda, Tanzania, and Uganda; to the west by the Republic of Congo, and the south by Angola and Zambia. The DRC became independent in 1960 after being founded as a Belgian territory in 1908. The country was later renamed Zaire in 1972 and became legally ratified five years later as the Democratic Republic of Congo in 1997 [2]. The DRC is currently comprised of over 200 languages and ethnicities, with French, Kingwana, Kikongo, Lingala, and Tshiluba being the nationally recognized languages [2].

\section{Corresponding author:}

Melody Okereke, BPharm (in view), mini-MBA

Faculty of Pharmaceutical Sciences, University of Ilorin, Kwara State, Nigeria; Email: melokereke30@gmail.com

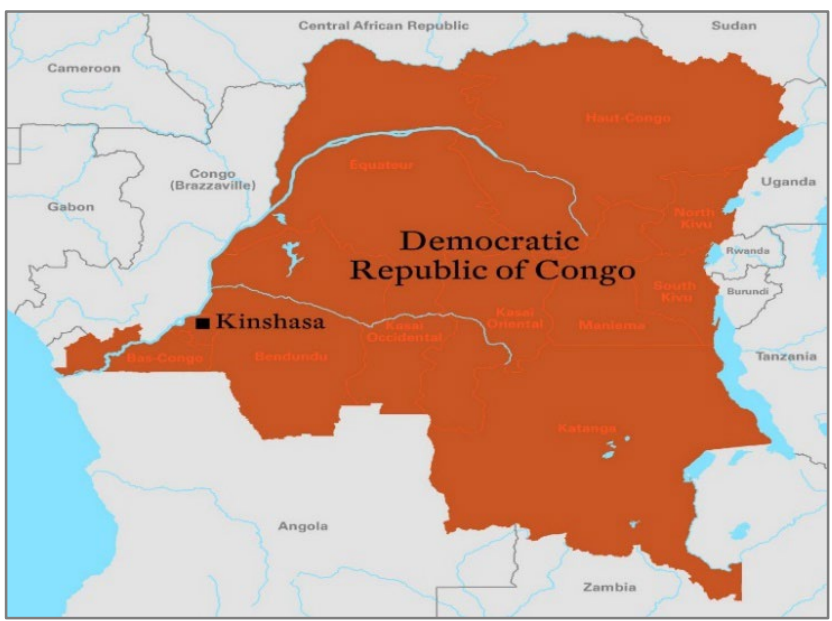

Figure 1 : Map of the Democratic Republic of Congo

Source: https://congoinconversation.fondationcarmignac.com/drc/

Ever since its civil conflict between 1997 and 2003, the DRC has faced periodic sociopolitical instability and unrest, and ongoing conflict persists today, notwithstanding that several peace treaties have been ratified in times past [3]. The conflict, termed "Africa's World War" resulted in the formation of geographic zones surmounted with persistent instability. Subsequently, about 2 million people suffered from internal displacement [3]. The DRC crisis has led to a breakdown of the healthcare system [4]. Between 1997 and 2004, an approximated 5.4 million deaths were recorded [3].

\section{Health Sector and Infrastructure of the DRC}

The health system of the DRC suffers several difficulties. The DRC has a history of possessing a performing and effective provincial primary healthcare (PHC) and referral system [2]. However, over the past three decades, the health system has deteriorated considerably, and is now overwhelmed by poor infrastructural mechanisms, insecurity, and an increasing burden of noncommunicable diseases [5]. In 2009, governmental expenditure on healthcare was amongst the least, at $\$ 2$ per capita, representing $2 \%$ of the gross domestic product [6]. According to a population needs estimate, $\$ 17.91$ would have to be invested by the DRC annually per citizen in 
order to provide adequate healthcare services [6]. However, the DRC has a historical tradition of district health systems focused on PHC. Hence, the Ministry of Health (MoH) assessed that swift renovation of these district health centers was required to better fulfill the demands imposed by post-conflict issues adequately [6]. In 2006, the DRC launched its Health Systems Strengthening Strategy (HSSS), which outlines the decentralized health district as the pillar of the Congolese health system, integrating $\mathrm{PHC}$ and first-referral services under one institutional framework for the delivery of health services. Eventually, the HSSS was accepted and became a significant step in restoring the lost trust of Congolese citizens in the health system [7].

\section{The Private Pharmaceutical Sector of the DRC}

Due to the abundance of unregulated and unauthorized pharmaceutical establishments, actual statistics in the private pharmaceutical sector remain uncertain [8]. In 2017, there were 30 local pharmaceutical manufacturers (LPMs), 91 approved and 171 unapproved distributors, and 109 licensed pharmacies in the DRC [8]. The majority of the 109 licensed pharmacies are located in Kinshasa, the capital city, and are all restricted to large metropolitan regions where consumers who have greater purchasing power dwell. The number of unregistered drug stores remains uncertain, but it is believed to be in the tens of thousands across the country. The Order of Pharmacists believes that there are roughly 5,000 unregistered drug shops in Kinshasa province alone [8].

\section{Pharmaceutical Education and Training in the DRC}

In terms of pharmaceutical training, the DRC has just 5 pharmacy training institutions [9]. According to a global report on pharmacy education in the Sub-Saharan African region, some of the difficulties faced by pharmacy training institutions in the DRC include insufficient academic capacity, shortage of infrastructure, poor accessibility to teaching resources, and the paucity of adequate research capacity [9]. According to the report, many attempts have been made to address these difficulties thus far, but they persist, creating long-standing hurdles to the provision of excellent pharmaceutical training in the country [9]. There are tendencies that these might result in a shortage of qualified and competent personnel with the necessary training to contribute to pharmaceutical manufacturing in the DRC. Given the poor state of pharmaceutical manufacturing in the country, it can therefore be argued that a shortage of skilled and competent pharmaceutical workforce with expertise in pharmaceutical manufacturing is a contributing factor.

\section{State of Local Pharmaceutical Manufacturing in the DRC}

Just $10 \%$ of pharmaceutical commodities consumed in the country are manufactured locally [8], and the capital city, Kinshasa is home to 21 of 30 LPMs [10]. Local pharmaceutical manufacturing in the nation is reliant on imported pharmaceutical materials and industrial machinery. As a result, the levies incurred due to importations raise prices and reduce price competitiveness, which discourages local manufacturing since only wealthy LPMs can sustain the high costs of importation and dominate the market, making local manufacturing relatively unattractive [8]. For example, in 2019, condoms and contraceptives that were imported into the DRC were subject to import taxes, tariffs, as well as other costs, including a 5\% administrative fee [8]. On the other hand, drug importations have been reported to be a major source of entry of substandard and counterfeit medicines into the supply chain, as reported in Nigeria [11]. Other challenges that LPMs encounter in the DRC include unsatisfactory and costly utilities, rising transportation expenditures, and corruption. Other African countries, particularly Nigeria, have reported similar incidents [12]. Consumers, on the other hand, believe that locally manufactured pharmaceutical products are of inferior quality, thus pharmacies are unwilling to stock them [8]. As a result, the country is forced to rely on the import of APIs, pharmaceutical products. For context, a 10-year analysis revealed an $842 \%$ rise in the number of imported pharmaceutical products into the DRC from 10,955.7 in 2010 to $103,206.665$ in 2020 due to the lack of manufacturing capacity which should otherwise have met local demands [13]. The excessive reliance of the DRC on imported APIs and necessary infrastructure for local pharmaceutical manufacturing were evident during the recent COVID-19 pandemic. This reliance is deeply worrying considering the possibility of any unforeseeable event which has the potential to disrupt drug importations imports- like the COVID-19 pandemic or new variants of the virus which are rapidly spreading across African countries [14]. Another concern worth highlighting is the issue of intellectual property (IP) rights imposed by big pharmaceutical companies on COVID-19 vaccines [15]. Even though COVID-19 vaccines were developed by big pharmaceutical companies, the vaccines were not readily available in African countries, including the DRC as the big pharma companies were not willing to share their technical know-how and manpower with developing countries in order to increase vaccine access and supply [15]. This invariably resulted in vaccine inequity [16] and it signaled the need for the African continent to intensify their pharmaceutical manufacturing capacity and the DRC is not an exception.

According to the World Health Organization (WHO) African Regional Office, the DRC recorded 207,500 deaths due to noncommunicable diseases in 2016 [17]. This is largely attributable to the demographic shift of the country due to rapid population growth [18] which has invariably resulted in a rise in the demand for safe, efficacious, and affordable pharmaceutical products that meet local demands. Notably, wars initiated during the last decade of the past century and the present COVID-19 pandemic led to a humanitarian crisis that affected the availability and security of medicines in the country [19]. Excessive reliance on imported drugs, especially in light of the recent COVID-19 pandemic, may potentially exacerbate problems encountered by the already weak health system of the DRC. There was a severe shortage of medicines in the 
country since major exporting countries went into lockdown during the pandemic, highlighting and reinforcing the need for the DRC to make self-sufficiency in pharmaceutical manufacturing a national priority. Given the considerable constraints that local manufacturers face in the DRC, it is uncertain that they will significantly expand their contribution to commercial sector supply. The biggest obstacle for local manufacturers is their inability to meet quality standards [8]. Moving on, the DRC must now reflect on the lessons learned over the last decade, as well as the COVID-19 pandemic, in order to step up measures aimed at strengthening its local pharmaceutical manufacturing capacity.

\section{Conclusion}

Political commitment, intersectoral collaboration, huge investment in undergraduate pharmaceutical science training, robust regulatory policies, local manufacture of APIs, technology transfer/know-how, pooled procurement, and adequate infrastructure are some of the enabling factors that can potentially enhance the state of pharmaceutical manufacturing in the DRC. For the coming years, strengthening local pharmaceutical manufacturing capacity to manufacture APIs local pharmaceuticals might continue to be a problem in Africa, as will ensuring conformity with international standards, which varies greatly throughout the region. The DRC, however, has the potential to develop a thriving local pharmaceutical manufacturing industry if the necessary mechanisms and resources -recommended herein- are in place.

The opinions expressed in this paper are those of the author.

\section{Acknowledgements: None \\ Funding: None \\ Conflicts of Interest: None}

\section{References}

1. Worldometers. DR Congo Population (LIVE). https://www.worldometers.info/worldpopulation/democratic-republic-of-the-congo-population/

2. Kalisya LM, Salmon M, Manwa K, Muller MM, Diango K, Zaidi $R$, Wendel SK, Reynolds TA. The state of emergency care in Democratic Republic of Congo. African Journal of Emergency Medicine. 2015 Dec 1;5(4):153-8. https://doi.org/10.1016/i.afjem.2015.08.001

3. Coghlan B, Brennan RJ, Ngoy P, Dofara D, Otto B, Clements M, Stewart T. Mortality in the Democratic Republic of Congo: a nationwide survey. The Lancet. 2006 Jan 7;367(9504):44-51. https://doi.org/10.1016/S0140-6736(06)67923-3

4. Alberti KP, Grellety E, Lin YC, Polonsky J, Coppens K, Encinas L, Rodrigue MN, Pedalino B, Mondonge V. Violence against civilians and access to health care in North Kivu, Democratic Republic of Congo: three cross-sectional surveys. Conflict and health. 2010 Dec;4(1):1-6.

5. Stasse S, Vita D, Kimfuta J, Da Silveira VC, Bossyns P, Criel B. Improving financial access to health care in the Kisantu district in the Democratic Republic of Congo: acting upon complexity. Global health action. 2015 Dec 1;8(1):25480.

https://doi.org/10.3402/gha.v8.25480
6. Rajan D, Kalambay H, Mossoko M, Kwete D, Bulakali J, Lokonga JP, Porignon D, Schmets G. Health service planning contributes to policy dialogue around strengthening district health systems: an example from DR Congo 2008-2013. BMC health services research. 2014 Dec;14(1):1-9. https://doi.org/10.1186/s12913-014-0522-4

7. Wembonyama S, Mpaka S, Tshilolo L. Medicine and health in the Democratic Republic of Congo: from Independence to the Third Republic. Medecine tropicale: revue du Corps de sante colonial. 2007 Oct 1;67(5):447-57.

8. World Bank. The Role of the Private Sector in Improving the Performance of the Health System in the Democratic Republic of Congo.

https://documents1.worldbank.org/curated/en/48757153995 8646859/pdf/131045-REVISED-23-1-2019-10-49-58WBDRCPSAEnglishWEB.pdf

9. International Pharmaceutical Federation (FIP). FIP pharmacy education in sub-Saharan Africa. https://www.fip.org/file/4812

10. DNB. Pharmaceutical and Medicine Manufacturing Companies In Congo, (Kinshasa). https://www.dnb.com/businessdirectory/companyinformation.pharmaceutical and medicine manufacturing.cd html

11. Okereke M, Anukwu I, Solarin S, Ohuabunwa MS. Combatting Substandard and Counterfeit Medicines in the Nigerian Drug Market: How Industrial Pharmacists Can Rise Up to the Challenge. INNOVATIONS in pharmacy. $2021 \mathrm{Jul}$ 26;12(3):15. https://doi.org/10.24926/iip.v12i3.4233

12. Okereke M, Adekunbi A, Ghazali Y. Why Nigeria Must Strengthen its Local Pharmaceutical Manufacturing Capacity. INNOVATIONS in pharmacy. $2021 \mathrm{Sep}$ 22;12(4):3. https://doi.org/10.24926/iip.v12i4.4208

13. CEIC. Democratic Republic of Congo Imports: Medicinal and Pharmaceutical Product.

https://www.ceicdata.com/en/indicator/democratic-republicof-congo/imports-medicinal-and-pharmaceutical-product

14. Okereke M. Spread of the Delta Coronavirus Variant: Africa Must Be on Watch. Public Health in Practice (Oxford, England). 2021 Oct 29. https://doi.org/10.1016/j.puhip.2021.100209

15. Okereke M, Essar MY. Time to boost COVID-19 vaccine manufacturing: The need for intellectual property waiver by big pharma. Ethics, Medicine, and Public Health. 2021 Dec;19:100710. https://dx.doi.org/10.1016\%2Fj.jemep.2021.100710

16. Okereke M. Towards vaccine equity: Should big pharma waive intellectual property rights for COVID-19 vaccines?. Public Health in Practice (Oxford, England). 2021 Nov;2:100165. https://doi.org/10.1016/i.puhip.2021.100165

17. World Health Organization (WHO). Democratic Republic of Congo. https://www.who.int/nmh/countries/cod en.pdf

18. Franco-Henao L, Rodriguez-Sumaza C, Borondo-Arribas $C$, Muzigirwa-Muke $E$. The demographic transition in the Democratic Republic of Congo: facts and challenges to reach a demographic dividend. African Population Studies. 2018 Oct 30;32(2).

19. Khan FM, Hasan MM, Kazmi Z, dos Santos Costa AC, Aborode AT, Ahmad S, Essar MY. Ebola and COVID-19 in Democratic Republic of Congo: grappling with two plagues at once. Tropical Medicine and Health. 2021 Dec;49(1):1-4. https://doi.org/10.1186/s41182-021-00356-6 